\title{
Successful aging and the epidemiology of HIV
}

This article was published in the following Dove Press journal:

Clinical Interventions in Aging

27 June 20II

Number of times this article has been viewed

\section{David E Vance' \\ Teena McGuinness' \\ Karen Musgrove ${ }^{3}$ \\ Nancy Ann Orel ${ }^{4}$ \\ Pariya L Fazeli ${ }^{2}$ \\ 'School of Nursing, ${ }^{2}$ Department of Psychology and Center for Research in Applied Gerontology, University of Alabama at Birmingham, ${ }^{3}$ Birmingham AIDS Outreach, Birmingham, AL, USA; ${ }^{4}$ Gerontology Program, Bowling Green State University, Bowling Green, $\mathrm{OH}$, USA}

Correspondence: David EVance School of Nursing, Room 456, I70 I University Blvd, University of Alabama at Birmingham, Birmingham, AL 352941210, USA

Tel +l 2059347589

Fax + I 2059752295

Email devance@uab.edu
Abstract: By 2015, it is estimated that nearly half of those living with HIV in the US will be 50 years of age and older. This dramatic change in the demographics of this clinical population represents unique challenges for patients, health care providers, and society-at-large. Fortunately, because of highly active antiretroviral therapy (HAART) and healthy lifestyle choices, it is now possible for many infected with HIV to age successfully with this disease; however, this depends upon one's definition of successful aging. It is proposed that successful aging is composed of eight factors: length of life, biological health, cognitive efficiency, mental health, social competence, productivity, personal control, and life satisfaction. Unfortunately, HIV and medication side effects can compromise these factors, thus diminishing one's capacity to age successfully with this disease. This article explores how HIV, medication side effects from HAART, and lifestyle choices can compromise the factors necessary to age successfully. Implications for practice and research are posited.

Keywords: HIV, AIDS, successful aging, spirituality, depression, hardiness

\section{Introduction}

The increased prevalence of HIV in older adults is attributable to three primary causes. First, older adults are contracting HIV in later-life. Incidence estimates from the Centers for Disease Control and Prevention (CDC) indicate that $15 \%$ of all new HIV cases occur in person 50 years of age and older. ${ }^{1}$ The increasing number of older adults who are contracting HIV in later life has been primarily attributed to the finding that older adults do not perceive that they are at risk for HIV because HIV has often been considered a disease of the young, intravenous drug users, or homosexuals. However, older adults may be more vulnerable to contracting HIV due to certain biological changes such as thinner mucosal membranes in the genitalia, anus, and vagina that tear more easily during sexual intercourse creating easy access for the virus to enter the body. ${ }^{2}$ Likewise, the introduction of sexual performance enhancing medications and establishing new and multiple sexual partnerships in later life due to divorce or death of a spouse may result in increased sexual contact and increased exposure to HIV. ${ }^{3}$ Second, the population in general is aging; as the "baby boomers" age, by sheer numbers those infected with HIV are also aging which contributes to the growing number of older adults with HIV. Third, and most importantly, highly active antiretroviral therapy (HAART) introduced in 1996-1997 has been effective in preventing viral replication for many patients, resulting in the opportunity for the body's immune system to be reconstituted. ${ }^{4}$ This allows many adults who respond well to such pharmaceutical treatment the chance to live and age with this disease. 
Different mechanistic classes (eg, nucleoside reverse transcriptase inhibitors, non-nucleoside reverse transcriptase inhibitors, protease inhibitors, fusion inhibitors, integrase inhibitors) of HIV medications continue to be developed, which means that as one combination of medications is no longer effective in suppressing viral replication, another combination can often be used in order to prolong life. ${ }^{5}$ As a result, of the 1.1 million adolescents and adults in the US infected with HIV, adults 50 years of age and older account for $24 \%$ of those living with HIV, $29 \%$ of those living with AIDS, and $35 \%$ of AIDS-related deaths. ${ }^{1}$ Furthermore, it is estimated that by 2015 , nearly half of those with HIV in the US will be 50 and older. ${ }^{6}$ This dramatic change in the demographics of the HIV population presents unique challenges for patients and health care providers.

The purpose of this article is to provide a general overview of the factors related to successful aging as they relate to the epidemiology of HIV. Using eight factors from Baltes and Baltes' definition of successful aging: the impact of HIV on length of life, biological health, cognitive efficiency, mental health, social competence, productivity, personal control, and life satisfaction are explored. ${ }^{7}$ An example of how these factors of successful aging interact with HIV is provided to show the complexity of aging with HIV. Implications for clinical interventions are provided along with directions for future research. It is important to note that the CDC has reported the incidence of HIV using age 50 and older as a major category and uses the term "older adult" to define those over the age of 50. Therefore, for the purpose of this paper, the standard convention of "older" with HIV is considered 50 and older. ${ }^{8}$

\section{Eight factors of successful aging with HIV}

There are a number of definitions and models of successful aging in the gerontological literature; ${ }^{3,9-11}$ some are very simplistic, incorporating only three major factors while others have over 20 major and minor factors with various interactions between each. Despite their differences, they all group certain factors together in biopsychosocial categories in order to predict what features are necessary to age successfully. Baltes and Baltes proposed a face valid, concrete definition of successful aging with eight factors that serve as an ideal rubric to explore the issues confronting those aging with HIV (Figure 1). ${ }^{?}$

\section{Length of life}

Basically, length of life consists of the number of years one remains alive. ${ }^{7}$ Obviously, being alive longer is a necessary factor of aging itself. Likewise, how long one survives into "old age" in order to be considered successful is dependent on one's perception of what old age is, and one's expectation for reaching such an age. Some may be pleased to reach their $70 \mathrm{~s}$ or 80 s, while others specifically aim to see their 90 s or 100s. Such hopes and expectations may be compromised for those with HIV. Being infected with HIV, stress from being diagnosed with such an expensive and stigmatizing disease, and the side effects from HAART can tax biological health and reduce life expectancy.

In a sample of 43,355 adults with HIV attending an HIV clinic in either North America or Europe, researchers examined life expectancy of patients on combination antiretroviral therapy during three study periods (ie, 1996-1999, 2000-2002, 2003-2005). During these time periods, 2056 $(4.7 \%)$ of the sample died. From these data, crude mortality rates were generated on life expectancy. Life expectancy at age 20 was $49.4(S D=0.5)$ years; thus, life expectancy is estimated to be approximately two-thirds that of the general population. Moreover, life expectancy was lower in men, those who contracted HIV through intravenous drug use, and those with lower initial baseline $\mathrm{CD} 4+$ cell counts. ${ }^{12}$

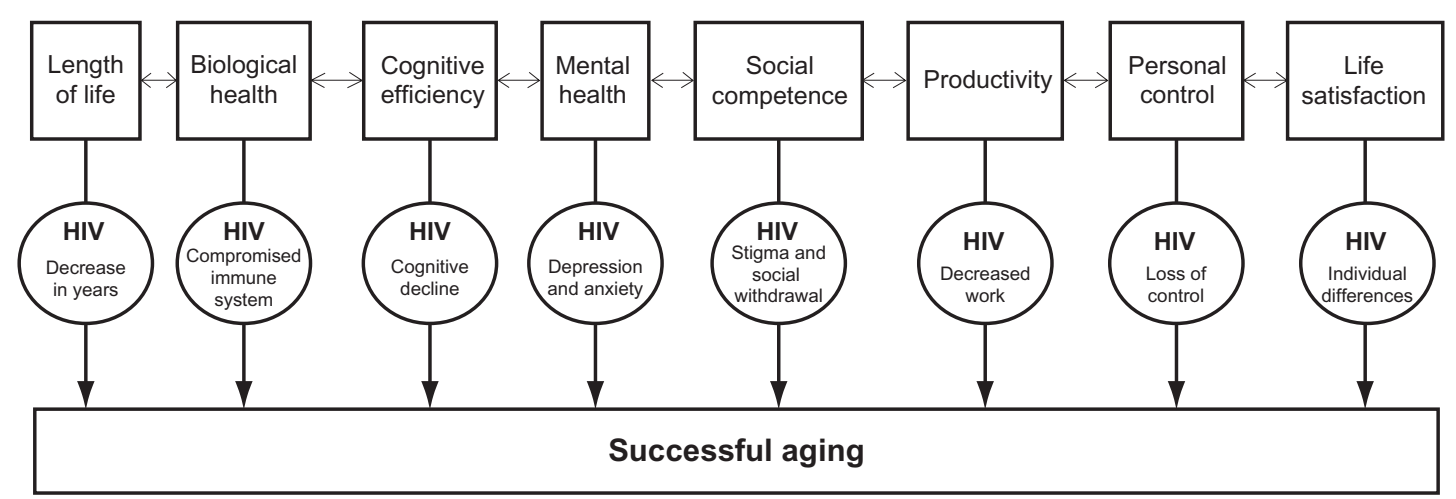

Figure I Factors of and obstacles to successful aging with HIV. 
Clearly, HIV does compromise length of life, albeit, these data must be interpreted with caution. First, these results are based upon data from 1996 to 2005, and since then, additional advancements in the treatment of HIV have been made. For example, more classes of medications have been developed along with a better understanding of HIV. Therefore, it is likely that life expectancy for those living with HIV has increased and may continue to do so. Second, these results are reporting average statistical projections; individual differences exist such that some adults with HIV will die sooner and others will far exceed the life expectancy reported here. Clearly, biological health is compromised which impacts life expectancy; however, it is important to be mindful that health promoting behaviors such as stress reduction, exercise, good nutrition, and substance use and smoking cessation are important considerations as well. These behaviors were not examined in the aforementioned life expectancy study.

\section{Biological health}

Biological health consists of how well the different systems of the body (eg, cardiovascular system, limbic system, nervous system) function and interact. ${ }^{7}$ The immune system is compromised by HIV making it less responsive to defend against infection. With age, the immune system is compromised by the involution of the thymus; this is important since the thymus assists in CD4+ cell maturation. ${ }^{13}$ Also with age, translocation of bacteria between the gastrointestinal mucosa and the circulatory system occurs more readily especially with alcohol use; this translocation introduces more bacteria into the body in which the immune system must fight, which thus contributes to early immune senescence. ${ }^{14-17}$ In fact, one study found elevated rates of plasma lipopolysaccharide and bacterial DNA (ie, measures of such translocation) in adults for at least 2 years after starting HAART. ${ }^{18}$ Despite these obvious ways in which biological health is compromised, HIV negatively affects biological health in two other important ways: HAART iatrogenic effects and polypharmacy.

First, although HAART has been effective in reducing replication of the virus in the body and thus allowing the immune system to be reconstituted, for some individuals negative side effects of these medications can emerge that can be bothersome, uncomfortable, and reduce quality of life, but in rare cases, they can even be life-threatening. Although such iatrogenic effects do not occur in everyone, when they do, they tend to be specific to the type of medication class of HAART being used. Nucleoside reverse transcriptase inhibitors are associated with the following iatrogenic effects: anemia, leucopenia, peripheral neuropathy, lactic acidosis, and pancreatitis. Non-nucleoside reverse transcriptase inhibitors are associated with the following iatrogenic effects: toxicity of the central nervous system, rash, and sleep problems. Finally, protease inhibitors are associated with the following iatrogenic effects: insulin resistance that can cause type 2 diabetes, diarrhea, gastrointestinal disorders, lipoatrophy, lipohypertrophy, and hyperlipidemia. ${ }^{5,19,20}$ For this last iatrogenic effect, medications such as statins are needed to control for high cholesterol levels caused by HAART. ${ }^{5}$

Second, polypharmacy is a concern with aging in general, but even more so for adults aging with HIV since they are already taking HAART medications that have well documented iatrogenic effects. As discussed, these iatrogenic effects can produce metabolic syndromes and comorbidities that in turn require additional medications. But with advancing age in general, renal and hepatic diseases are more common, with poorer functioning in these systems, and the processing and clearance of by-products of these medications becomes more difficult, which can further impair biological health and lead to the formation of comorbidities. ${ }^{20,21}$ In a study of 1478 outpatients at an HIV clinic, researchers found that with age in general, the average number of comorbidities rose with each decade of life, with those in their $20 \mathrm{~s}, 30 \mathrm{~s}, 40 \mathrm{~s}$, 50 s, and $>60$ s having $2.20,2.89,3.96,4.40$, and 4.52 comorbidities, respectively. Likewise, they found the average number of prescribed medications rose dramatically with each decade of life, with those in their $20 \mathrm{~s}, 30 \mathrm{~s}, 40 \mathrm{~s}, 50 \mathrm{~s}$, and $>60$ s taking $7.43,10.22,11.72,12.48$, and 14.82 prescribed medications, respectively. ${ }^{22}$ Clearly, the possibility of drug interactions also increases with the number of medications taken.

Polypharmacy in older adults with HIV is further complicated by complementary and alternative medicines such as herbs and vitamin supplementation that older adults with HIV may be taking to augment their biological health. In fact, one survey showed that $60 \%$ of patients with HIV use complementary and alternative medicines to self-treat many of their HIV-related issues. ${ }^{23}$ Unfortunately, some studies show that those who use such complementary and alternative medicines (eg, vitamin supplementation, herbs, traditional healing practices) were less adherent to their medication schedules or medical appointments. ${ }^{24,25}$ Thus, it is essential for clinicians to vigilantly monitor polypharmacy and potential side effects.

\section{Cognitive efficiency}

Cognitive efficiency is defined as the optimal neurological integrity necessary to form and process thoughts and ideas, remember information, reason, problem solve, and plan 
in order to effectively negotiate ones' social and physical environment. ${ }^{7}$ Fortunately, due to the effectiveness of HAART, HIV-related dementia is much less common than it used to be and is now estimated to be prevalent in about $2 \%$ of this clinical population. ${ }^{26}$ Regardless, numerous studies show that in general, older adults with HIV perform worse on cognitive measures (eg, attention, memory, speed of processing, reasoning) compared to same-aged peers without HIV and younger adults with HIV. ${ }^{20,27-30}$ Likewise, these same studies also show younger adults with HIV perform worse on cognitive measures compared to same-aged peers without HIV. This decline in cognitive efficiency is of concern since it can negatively affect emotional equilibrium (problem solving an emotional obstacle) and performance on Instrumental Activities of Daily Living (IADLs) such as medication adherence (remembering to take medications), managing finances (reasoning how much one owes), and driving (visual speed of processing needed to avoid automobile crashes). ${ }^{21}$

There are many causes of such cognitive declines associated with HIV and aging. First, HIV creates an inflammatory response in the body and the brain that can be damaging to neurons. ${ }^{31}$ Also, reconstitution of the immune system (the process of CD4+ cells being regenerated) can also create an inflammatory response to the nervous system which can negatively impact cognitive functioning. ${ }^{5,32}$ This problem seems to be particularly relevant for those whose CD4+ count drops below 200 cells/ $\mu \mathrm{L}$ and it appears to have a significant and long-term impact on neurological and subsequent cognitive functioning. ${ }^{28,29}$ Second, past or present substance use can obviously interfere with cognitive functioning. ${ }^{21,28,29,31}$ Finally, stress, depression, and anxiety have also been shown to negatively contribute to cognitive functioning. ${ }^{28,31}$

In addition to these causes from HIV itself, many adults with HIV contend with co-occurring conditions such as substance use and hepatitis $\mathrm{C}$ infection, which can also compromise cognitive functioning. In a study comparing neuropsychological functioning between 187 African American men with HIV to 310 African American men without HIV, researchers found that these men with HIV performed worse on a number of cognitive measures (eg, Grooved Pegboard). ${ }^{33}$ Furthermore, these researchers categorized this sample into four groups by alcohol use during the past 12 months: 1) nondrinkers, 2 ) light drinkers ( $<7$ drinks/ week), 3) moderate drinkers (7-21 drinks/week), and 4) heavy drinkers ( $>21$ drinks/week). Controlling for a number of potential confounds (eg, substance use, education), alcohol use and HIV serostatus demonstrated an interactive effect. As expected, those with HIV who were heavy drinkers exhibited poorer cognitive functioning compared to everyone else. Similarly, the use of other drugs (eg, crystal meth, cocaine) has also been shown to impair cognitive efficiency in this clinical population. ${ }^{28,34}$ Likewise, hepatitis $\mathrm{C}$ coinfection has also been shown to further impair cognitive efficiency in those with HIV. In a sample of 45 adults with HIV and 20 adults with both HIV and hepatitis $\mathrm{C}$, researchers found the adults with hepatitis $\mathrm{C}$ performed worse on measures of fine motor functioning and visual memory. ${ }^{35}$ However, when both groups were placed on HAART, differences in their cognitive performance were no longer detected 6 months later. Regardless of this improvement, concerns remain that as people with HIV age with substance use issues and/or hepatitis $\mathrm{C}$, this may compromise their cognitive efficiency.

Given these main causes, a number of methods have been suggested to either prevent cognitive loss or improve such cognitive functioning once such declines develop. ${ }^{31}$ The first method suggested is preventing HIV from crossing the blood-brain barrier by keeping the amount of the virus in the body low through adherence to HAART; having less HIV in the circulatory and lymphatic systems means that there will be less contact of the virus with the brain, especially glial cells which make up $85 \%$ of the brain. ${ }^{36}$ Studies show that once HIV crosses the blood-brain barrier, it can infect glial cells which support neuronal functioning; once infected, the glial cells eventually die and during this process they produce quinolic acid, a neurotoxin. ${ }^{36,37}$ A second method of preventing cognitive loss or improving cognition is promoting healthy lifestyle choices such as engaging in physical exercise, having good sleep hygiene, reducing stress, eating nutritious foods, and avoiding smoking and excessive alcohol and drug use. The general tenet is that - what is good for the body is also good for the brain, and thus cognition. ${ }^{31}$ A third method is treating mood disorders such as anxiety and depression. Depression and anxiety are "ruminative" disorders; in other words, during these disorders, one ruminates/perseverates (ie, thinks repeatedly) about a particular problem(s); this constant focus depletes cognitive resources that are needed to perform other cognitive tasks. ${ }^{38}$ Therefore, cognitive abilities are compromised with depression and anxiety. Fortunately, studies demonstrate that treating such mood disorders with antidepressants actually improves some cognitive abilities. ${ }^{39-41}$

\section{Mental health}

Mental health consists of the emotional equilibrium necessary to interact effectively with the social and physical environment as well as enjoy life. ${ }^{7}$ Regrettably, HIV has been associated 
with poor mental health in two ways: 1) poor mental health can predispose one to HIV infection and, 2) a diagnosis of HIV can result in poor mental health. First, poor mental health can lead to poor judgment and decision-making, which results in placing oneself in a situation where exposure to HIV infection is increased. As shown in numerous studies, those with chronic relapsing psychiatric illnesses such as schizophrenia, bipolar disorder, and substance abuse are at increased risk of HIV infection. ${ }^{42-44}$ For example, in a sample of 101 adults with co-occurring bipolar and substance use disorders, the incidence of risky sexual behavior was observed to be quite high; $75 \%$ reported being sexually active in the last 6 months along with high-risk behaviors including unprotected sexual intercourse (69\%), having sex with multiple partners $(39 \%)$, having sex with prostitutes ( $24 \%$, men only), and trading sex for favors such as money or drugs $(10 \%) .{ }^{45}$ Clearly, among those infected with HIV with severe psychiatric comorbidities, the extra mental and physical strain of HIV along with the neurological impact of HIV on the nervous system will possibly make coping with HIV while aging more difficult. Hypothetically, with advancing age and the subsequent development of mild cognitive impairment and the advancement of early dementia, some individuals with HIV with such comorbid psychiatric conditions may experience even more compromised judgment. This may result in increased risky sexual behavior that may lead to reinfection (ie, being re-exposed to a different strain of HIV and/or perhaps a drugresistant strain) and further compromise their immune system, biological health, and length of life.

Second, HIV is a stigmatizing, life-threatening disease often associated with fear, guilt, and uncertainty; thus, a diagnosis of HIV can result in intense anxiety, depression, and even suicidal ideation. In fact, the prevalence of anxiety and depression remains remarkably high across the lifespan, even into later life. In the prior study on comorbidity prevalence across the life span of 1478 HIV outpatients, the prevalence of anxiety in those in their $50 \mathrm{~s}$ or $60 \mathrm{~s}$ and greater were $20.3 \%$ and $12.3 \%$, respectively; likewise, the prevalence of depression in the same two age groups were $45.8 \%$ and $36.4 \%$, respectively. ${ }^{22}$ Although these rates are reduced in the much older group, this may also reflect survival bias in that those who are successfully aging may be hardier in general. Clearly, screening and monitoring mood disturbances such as these are important mental health issues for patient care, but especially for those who may be experiencing extreme mood disturbance, specifically suicidal ideation.

Suicidal ideation and suicidal rates are higher in older adults (especially men) and those with HIV; therefore, there is concern that as people age with HIV, they will be more vulnerable to these mental health challenges. ${ }^{38}$ Following an initial HIV diagnosis of 207 women in New York, researchers found that $27 \%$ and $42 \%$ reported attempting suicide within the first week and the first month, respectively. ${ }^{46}$ Based on the literature, it appears that over time, the severity of suicidal ideation subsides as people learn how to deal with their diagnosis but may not subside permanently; when symptoms of HIV emerge, such suicidal ideation may increase. ${ }^{47}$ Since comorbidities and other health complications increase with age, there is concern that those aging with HIV will also experience more suicidal ideation and be at risk for suicide. Nichols and colleagues found that out of 172 older adults with HIV, $17 \%$ considered suicide within the past 6 months. ${ }^{48}$ Likewise, in a study of 113 older adults with HIV, 27\% reported suicidal ideation within the past week. ${ }^{49}$ Clearly, this represents a sizeable minority of older adults with HIV vulnerable to these extreme mental health challenges.

Based on this prevalence, it is important to identify potential areas that may lead to such anxiety, depression, and especially suicidal ideation in those aging with HIV. From the literature, a number of stressful factors that may play a role in suicidal ideation in this clinical population have been identified for intervention; these include changes in appearance (eg, lipoatrophy in the face), HIV-related stigma, ageism, declining health, fatigue, neurological changes related to poor cognitive functioning, declines in social support and loneliness, and financial distress. ${ }^{38}$ Thus, the following recommendations were posited to improve mood and reduce negative affect and the prevalence of suicidal ideation; these include financial planning to reduce financial distress, learning to access spiritual supports, counseling, antidepressants, and addressing healthy lifestyle choices (eg, exercise, stress reduction).

\section{Social competence}

Social competence consists of the ability to process social interactions constructively to secure physical, emotional, and intimate needs. ${ }^{7}$ From the perspective of social exchange theory, being socially competent entails possessing a sense of worth in which one can socially exchange with another's worth. ${ }^{50}$ With a diagnosis of HIV, there often comes a sense of being "damaged goods" or "possessing a questionable character" that compromises this sense of worth. This diminished sense of worth can be internalized by the person with HIV or externalized by the person with whom he or she is socially interacting and exchanging. This diminished worth can be further threatened by ageism, homophobia, and/or 
lack of education or financial means. ${ }^{51}$ Attractiveness can even play a part; those who experience disfiguring of the face due to lipoatrophy caused by HAART may experience a further loss of social worth.

As social worth decreases, social competence may be compromised, and this may result in social withdrawal which is often observed with HIV, especially older adults with HIV. ${ }^{48}$ For example, in a sample of 160 older adults with HIV, 71\% reported living alone, only $47 \%$ reported having a committed intimate relationship, and $57 \%$ reported that their emotional needs were unmet. Furthermore, this sample reported that their primary social supports were others with HIV. $^{52}$ This becomes particularly germane given that with age in general, social networks become smaller due to attrition from poor health, lack of financial resources required to engage in social activities (eg, traveling, dining out), and death of others in their social network. ${ }^{53}$

Clearly, social competence is needed to build social supports and networks that are necessary for successful aging. However, the first step is to overcome internalized HIV stigma; if an older adult with HIV experiences this, it will be difficult to interact and "socially exchange" with others. Counseling can be helpful in accepting one's role as a person "who happens to be HIV positive". Support groups can also be a safe place to confront HIV stigma and learn to move beyond the diagnosis. Likewise, involvement in supportive religious/spiritual communities can also be a source of social support and help build one's social network.

\section{Productivity}

Productivity consists of how well one is able to support one's self and one's goals as well as contribute to group goals. ${ }^{7}$ With a diagnosis of HIV, there are often somatic complaints such as fatigue, diarrhea, and depression and other health issues that interfere or preclude engaging in such goals, one of those primary goals being employment for those who are not eligible for retirement income.

In a sample of 141 HIV symptomatic gay men in 1995 , researchers followed them over a 30-month period to observe these participants' change in work status. In general, employment status for most (79\%) of these men was continuous over time; they were employed full-time (30\%), employed parttime $(9 \%)$, or unemployed $(40 \%)$. For those $(31 \%)$ whose employment status changed from the beginning of this study period, they either: increased their hours (13\%), decreased their hours $(8 \%)$, terminated employment $(4 \%)$, or showed a wavering pattern (6\%). By the end of the study period, $52 \%$ were either unemployed or were working fewer hours. ${ }^{54}$ This figure represents a particular challenge to successful aging since employment is an important source of productivity as well as health insurance. Work can be a rich source of identity and provides contact to interact with others, which can help build social networks; also, work is a means of social worth. In this study, researchers found that even when the health of these men did improve, this did not precipitate a return to work. In further analysis of these data, several barriers related to partial employment and unemployment were identified including fear of losing disability benefits, physical limitations due to health problems, psychiatric problems (ie, depression, dysthymia), cognitive problems (ie, executive functioning), and lower education level. Although age was not an identified barrier in this study, this may be because the age of the sample was quite young $\left(M_{\text {age }}=40, S D=8\right)$. Today however, age may be an important factor; since many adults with HIV are aware that they are aging with this disease, the urgency to work and plan for retirement is important, especially in lieu of the current economic uncertainty when disability benefits and other social assistance programs are threatened.

For those aging with HIV, there are a number of challenges to their productivity, specifically surrounding the issues of work, retirement, and being able to support oneself financially. First, for many adults aging with HIV, they may have been diagnosed in the late 80 s and early 90 s when poor prognoses were dispensed and survival was not expected. As such, they may have reduced their work hours and therefore received less money, backed away from pursuing careers, were sick and needed to go on disability, or opted for early retirement. Believing that death was imminent, many may have amassed enormous debts in order to live the remainder of their days in relative comfort. But with the nascent of HAART in the second half of the 90s, optimism for better prognoses and expected survival increased. Instead of dying, many had to learn to live again; this social phenomenon caused by the effectiveness of HAART has been referred to as Lazarus Syndrome. ${ }^{55}$ As a result, many have found themselves in one of many precarious financial straits. First, some may have sold their life insurance in viatical settlements at a reduced rate only to find that they would be paying on a policy that is worthless. Second, others may have had to face bankruptcy for amassing enormous bills during a time they thought they were going to die; thus, their credit is severely compromised. And third, some may not have stayed employed and received disability benefits or early retirement only to find that years later, in their 50 s and 60 s, that they have much longer to live. However, living on a fixed 
income within the context of rising costs and diminishing social programs may not be sufficient to support their lifestyle such as it is.

For those who are healthy enough to decide to return to work in later life, this option is challenging as well. First, for those on disability or retirement, returning to work can threaten the continuation of receiving such benefits, even if work is part-time. Negotiating part-time or full-time employment can certainly be a stressful situation requiring a great deal of finesse and assistance. ${ }^{54}$ Second, finding a job can be difficult especially when one is older and has an inconsistent work history. This situation is further problematic given the subtle influence of ageism in the workplace. ${ }^{56,57}$ Employers may be reluctant to hire older adults for several reasons: 1) they may need retraining and retooling especially in lieu of the advancements made in technology, 2) they will probably retire in a few years, and 3 ) they may be a burden on the company's health insurance plan. ${ }^{58}$ These challenges are quite real; however, how to confront them remains elusive.

\section{Personal control}

Personal control consists of one's sense of influence over oneself and his or her environment. ${ }^{7}$ This concept is intricately related to the concept of social competence as well, in that personal control is used in a social context to establish social worth. But when one is diagnosed with HIV, that sense of control is compromised because one can no longer "not" have HIV; it is permanent and at this point beyond one's control regardless of any future actions. Likewise, given the stigmatizing nature of HIV, one's social worth is subsequently compromised; one is now stigmatized by default. Furthermore, a diagnosis of HIV contains uncertainty about if or when one will become ill, disabled, or die; this uncertainty is observed in many other life-threatening diseases (eg, cancer) as well and is referred to as Damocles Syndrome. ${ }^{59}$

In the story of King Damocles, a servant remarked during a banquet that it must be easy to be the king and be waited upon. King Damocles responded by having the servant sit at the head of the table, removed his sword, tied the hilt of the sword to a beam high above the servant's head using a single hair from a horse's tail. With the point of the sword positioned over the servant, King Damocles instructed the servant to enjoy the banquet in his stead. Not having control over the situation, the servant obviously could not enjoy the banquet for fear that the hair would break at any moment, allowing Damocles' sword to fall and impale him.

Such loss of personal control and uncertainty may be exacerbated in those who are older with HIV. As mentioned, individuals aging with HIV may not be in a position to rally adequate financial, social, and physical resources to exert control in their lives. This may be further compromised by declines in cognitive efficiency and biological and mental health. Such a loss of personal control is tantamount to helplessness and hopelessness, which may contribute to feelings of anxiety, depression, and suicidal ideation.

Coping with such a loss of personal control is an essential aspect of successful aging with HIV. Passive and active coping techniques are ways of dealing with the emotional aspect of such helplessness. Passive coping techniques entail mitigating negative emotions through avoidance strategies. These can be subtle such as watching TV or they can be extreme such as abusing alcohol and drugs. While passive coping techniques are needed to escape and assuage negative feelings, they do not address the source of the problem. Active coping techniques are necessary to address the source of negative feelings whether it be fear of developing dementia, worry about not having enough money to retire, or concern about being alone. Therefore, active coping techniques are needed to address such issues whether they be learning more about how to stay cognitively efficient, consulting a financial advisor, or joining a support group.

Many individuals when first diagnosed with HIV experience this loss of personal control; this is evident in the elevated rate of suicide attempts $(42 \%)$ within the first month of being diagnosed. ${ }^{46}$ Fortunately, many learn to adapt through a combination of passive and active coping techniques. Moreover, for some this loss of personal control may be reestablished by redefining the extent of their personal control. For example, "I may not be able to get rid of HIV, but I can take my medications consistently and try to keep a positive outlook". By focusing on what one can "do" or can "try", one reestablishes a sense of personal control. In the successful aging literature, this "can do" attitude is known as hardiness.

Basically, hardiness refers to the ability to endure negative stressors. Research demonstrates that hardiness facilitates successful aging. ${ }^{60}$ In fact, some studies even show that those who score higher on measures of hardiness have a more robust immune system and better psychosocial outcomes than those with a lower score. ${ }^{61}$ Although some researchers consider hardiness to be a trait and therefore nonmalleable, ${ }^{62}$ others consider it a personal paradigm or perspective.$^{60}$ As a perspective, it is therefore something that can be developed, learned, and even unlearned. As such, some researchers have suggested individual cognitive-behavioral programs, based on principles of motivational interviewing, to help ameliorate 
hardiness in adults with HIV with the focus on helping them to age successfully. Within these programs, individuals set their own goals and are instrumental in devising strategies to improve their sense of personal control and hardiness as they use a combination of passive and active coping strategies. ${ }^{60}$ Clearly, whether it is successful aging with HIV or any other life-threatening disease, it is important to develop and maintain a sense of personal control in one's life.

\section{Life satisfaction}

Life satisfaction consists of the quality and meaning one attributes to his or her existence. ${ }^{7}$ Although related to the concept of personal control in that they are both personal perceptions, life satisfaction is a global phenomenological concept. Moreover, how much one is satisfied with one's life cannot be reduced into a formulaic statement. In fact, one could surmise that life satisfaction is tantamount to the concept of successful aging itself. Clearly, length of life, biological health, cognitive efficiency, mental health, social competence, productivity, and personal control make up a part of whether one is satisfied with life, and therefore aging successfully. However, one's perception of life satisfaction remains elusive. For example, $\mathrm{Mr} \mathrm{X}$, who has been living with HIV since the early 80s may have lost several close friends and partners, be living on a severely limited fixed income, be in poor health and unable to work, does not have a partner, yet be quite satisfied with his life and considers himself to be aging quite successfully. Meanwhile, Mr Y who was diagnosed in 2001 when the efficacy of HAART was well-established, is very healthy, exercises every day, has a partner and a thriving business, yet despite such pleasant circumstances, is not satisfied with his life and considers himself to be aging unsuccessfully. Thus, life satisfaction appears to be quite a subjective construct.

Other factors obviously play an important role in determining whether individuals are satisfied with their lives as they age with HIV, such as spirituality. In a mixed-methods design, 50 adults with HIV $\left(M_{\text {age }}=40\right.$ years; range $=31-56$ years) were assessed on a number of spirituality and healthrelated factors. Interestingly, $72 \%$ reported that their spirituality changed after being diagnosed with HIV; furthermore, when asked "Do you consider HIV to be a blessing?" 44\% reported that they did. This was surprising but when asked why, many indicated that their HIV diagnosis helped them to reprioritize their lives and focus on the things that truly matter. Participants were also asked "Do you feel that you are aging well?" ( $1=$ not at all; 5 = extremely); as a group, they responded within the "moderately" category $(M=3.20$;
$S D=1.21)$. Further analysis revealed that those who thought they were aging successfully were more likely to be those whose spirituality changed after being diagnosed with HIV $(r=0.33)$ and reported HIV to be a blessing $(r=0.36){ }^{63,64}$ From this study, meaning, in this case derived from spirituality, is important in attributing whether one is aging successfully and perhaps satisfied with life.

\section{The complexity of aging with HIV}

The factors necessary for successful aging with HIV presented in Figure 1 are dynamic and interact with each other in innumerable ways. An example of this is provided in Figure 2. Starting with cognitive efficiency, for some aging with HIV, cognitive declines may be ineluctable. Such cognitive decline has been observed in the literature to be related to poor medication adherence (Path A). ${ }^{65}$ As a result, poor medication adherence can create viral resistance to the medication and result in poor biological health (Path B), which in turn can shorten one's length of life (Path C) and compromise neurological systems resulting in more cognitive decline (Path D). Further exacerbation of cognitive efficiency can then subsequently result in decreased social competence, productivity, and mental health (Paths E); if one is experiencing cognitive declines, this can interfere with socializing with others, poor job performance, and lead to depression. With declines in social competence, decreased productivity, and mental health, these can interact among themselves to further exacerbate these declines (Paths F). For example, increased depression and anxiety may interfere with one's employment and lead to social withdrawal. Finally, the collective influence of cognitive decline, poor biological health, shorter length of life, and decreased social competence, productivity, and mental health will negatively affect one's perception of life satisfaction (Paths G).

\section{Implications for clinical intervention and research}

There are innumerable areas of clinical intervention research that should be investigated, but with increasingly limited funding and resources, selecting such areas must be made judiciously. The definition of successful aging (Figure 1) provides scaffolding in which to direct such efforts. The two predominant areas for clinical intervention research obviously include length of life and biological health; clearly, more is needed in drug development and management of comorbidities in order to help adults live longer and better with this disease. Furthermore, with the involution of the thymus with age and HIV, looking into new ways to boost thymic function 


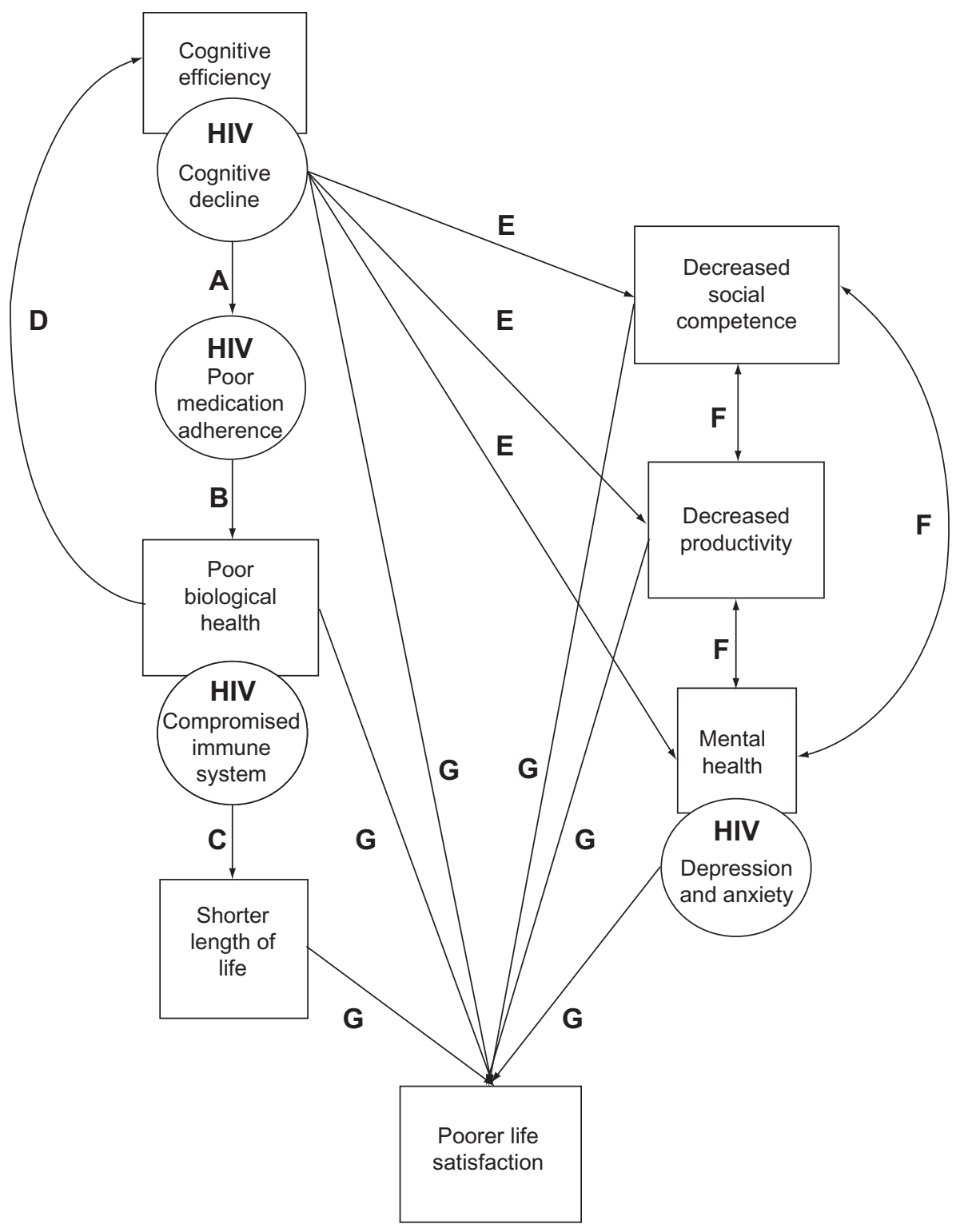

Figure 2 Example of the interaction of the factors of successful aging with HIV.

such as sex steroid ablation in order to help the immune system function better is an important area of research. ${ }^{13}$

Now that HIV infection has become a chronic disease for many people who tolerate the medications, further emphasis must also focus on pharmacological aspects of HIV disease management with age-related side effects. Specifically, as viral resistance to certain medications develop, it is not clear whether older adults with this disease will be able to effectively switch to previous medications that years before were effective in controlling the virus. Likewise, with aging comes poorer hepatic and renal functioning, so how older individuals tolerate such HIV medications will need to be reexamined since many of these medications were not tested with older adults.
Ostensibly, clinical interventions to improve the psychosocial factors of successful aging must also be considered given how they dynamically impact everyday functioning and affect biological health and length of life. One area of particular need will be clinical interventions to protect and improve cognition. Although recommendations for improving general cognition through healthy lifestyle choices have already been posited, more targeted interventions to improve certain cognitive abilities should be investigated. One pilot study used a pre-post, two-group, experimental design to examine whether visual speed of processing training improved cognitive functioning in 52 older participants with HIV $\left(M_{\text {age }}=51.5\right.$ years); typically this cognitive remediation therapy is used in normal 
community-dwelling older adults to improve their driving and instrumental activities of daily living performance. ${ }^{31}$ Researchers randomized these participants either into the speed of processing (experimental) condition or into a no-contact (control) condition. Those in the experimental condition received 10 hours of an interactive computer gaming program that was specifically designed to increase the rate in which participants processed visual information. Not only did this experimental group improve upon a measure of visual speed of processing (ie, Useful Field of View ${ }^{\circledR}$ test), this transferred to improvements on the Timed Instrumental Activities of Daily Living test. ${ }^{66}$ Such noninvasive, nonmedical cognitive interventions are favored, especially since they are inexpensive and do not place medication demands on a clinical population for which there is already a heavy pharmaceutical burden. ${ }^{22}$

Lipoatrophy of the face as well as the body is another important area for research. As mentioned, such fat wasting in the face can be extremely devastating in terms of its impact on social competence. Lipoatrophy is more common with thymide analogs of HAART but also occurs more frequently with age. Unfortunately, there are few effective treatments for reversing the effects of lipoatrophy and those that exist are normally not covered by health insurance. ${ }^{67}$

Finally, another area in which clinical interventions are needed to improve the psychosocial factors of successful aging is productivity, specifically financial planning. As alluded to earlier, HIV is an expensive disease with medication costs running into the tens of thousands of dollars per year; in lieu of diminishing social programs and public assistance, this is an especially difficult hardship for those who do not have health insurance. Beyond that, many are facing an uncertain retirement, well aware that they do not have the means to live at a decent standard of living. This is further complicated by the fears of uncertain economic conditions that foster severe cutbacks in social programs for the indigent, infirm, and elderly. There are no easy answers to these mounting concerns; but clearly innovative ideas are needed to address what can be done to help individuals age with this disease.

\section{Conclusion}

Within the past few years, the topic of aging with HIV has emerged as one of the leading issues surrounding HIV care. At the 18th International AIDS Conference in July 2010, over 20,000 HIV scientists, activists, and people living with HIV gathered in Vienna, Austria to discuss several of the pressing topics surrounding HIV and AIDS care. That year, this change in the demographics of aging with HIV was recognized with 26 workshops, seminars, and other venues focusing on this topic. ${ }^{68}$ As the population of older adults with HIV increases, understanding the factors important to facilitate successful aging with this disease will become much more important.

\section{Disclosure}

No conflicts of interest were declared in relation to this paper.

\section{References}

1. Centers for Disease Control and Prevention. HIV/AIDS among persons aged 50 and older: CDC HIV/AIDS facts. 2008, Washington, DC: US Department of Health and Human Services.

2. Coleman CL. Revisiting HIV/AIDS. Men in Nursing. 2006;1:20-27.

3. Vance DE, Robinson FP. Reconciling successful aging with HIV: a biopsychosocial overview. J HIV AIDS Soc Serv. 2004;3:59-78.

4. Perez JL, Moore RD. Greater effect of Highly Active Antiretroviral Therapy on survival in people aged $>50$ years compared with younger people in an urban observational cohort. Clin Infect Dis. 2003; 36:212-218.

5. Raper JL. The medical managment of HIV disease. In: Durham JD, Lashley FR, editors. The Person with HIV/AIDS: Nursing Perspective (4th ed). New York: Springer Publishing Company; 2010: 221-291.

6. Kirk JB, Goetz MB. Human immunodeficiency virus in an aging population, a complication of success. J Am Geriatr Soc. 2009;57: 2129-2138.

7. Baltes PB, Baltes MM. Psychological perspectives on successful aging: the model of selective optimization with compensation. In: Baltes PB, Baltes MM, editors. Successful Aging: Perspectives from the Behavioral Sciences. Cambridge, UK: Cambridge University Press; 1990:1-34.

8. Stoff D. Mental health research in HIV/AIDS and aging: problems and prospects. AIDS. 2004;18:S3-S10.

9. Kahana E, Kahana B. Successful aging among people with HIV/AIDS. J Clin Epidemiol. 2001;54:S53-S56.

10. Parker MW, Bellis JM, Bishop P, et al. A multidisciplinary model of health promotion incorporating spirituality into a successful aging intervention with African American and white elderly groups. Gerontologist. 2002;42:406-415

11. Rowe JW, Kahn RL. Successful aging. Gerontologist. 1997;37: 433-440.

12. The Antiretroviral Therapy Cohort Collaboration. Life expectancy of individuals on combination antiretroviral therapy in high-income countries: a collaborative analysis of 14 cohort studies. Lancet. 2008;372:293-299.

13. Holländer GA, Krenger W, Blazar BR. Emerging strategies to boost thymic function. Curr Opin Pharmacol. 2010;10:443-453.

14. Appay V, Sauce D. Immune activation and inflammation in HIV-1 infection: causes and consequences. Am J Pathol. 2008;214:231-241.

15. Desai S, Landay A. Early immune senescence in HIV disease. Curr HIV/AIDS Rep. 2010;7:4-10.

16. Deeks SG. Immune dysfunction, inflammation, and accelerated aging in patients on antiretroviral therapy. Top HIV Med. 2009;17:118-123.

17. Redd AD, Gray RH, Quinn TC. Is microbial translocation a cause or consequence of HIV disease progression? J Infect Dis. 2011;203: 744-745. 
18. Jiang W, Lederman MM, Hunt P, et al. Plasma levels of bacterial DNA correlate with immune activation and the magnitude of immune restoration in persons with antiretroviral-treated HIV infection. $J$ Infect Dis. 2009;199:1177-1185.

19. Bhavan KP, Kampalath VN, Overton ET. The aging of the HIV epidemic. Curr HIV/AIDS Rep. 2008;5:150-158.

20. Burrage JW Jr, Vance DE. Aging and the person infected with HIV. In: Durham JD, Lashley FR, editors. The person with HIV/AIDS: nursing perspective (4th ed). New York: Springer Publishing; 2010:505-517.

21. Vance DE. Aging with HIV: bringing the latest research to bear in providing care. Am J Nurs. 2010;110:2-7.

22. Vance DE, Mugavero M, Willig J, Raper JL, Saag MS. Aging with HIV: a cross-sectional study of co-morbidity prevalence and clinical characteristics across decades of life. J Assoc Nurses AIDS Care. 2011;22:17-25.

23. Mikhail IS, DiClemente R, Person S, et al. Association of complementary and alternative medicines with HIV clinical disease among a cohort of women living with HIV/AIDS. J Acquir Immune Defic Syndr. 2004;37:1415-1422.

24. Jernewall N, Zea MC, Reisen CA, Poppen PJ. Complementary and alternative medicine and adherence to care among HIV-positive Latino gay and bisexual men. AIDS Care. 2005;17:601-609.

25. Owen-Smith A, Diclemente R, Wingwood G. Complementary and alternative medicine use decreases adherence to HAART in HIV-positive women. AIDS Care. 2007;19:589-593.

26. Heaton RK, Clifford DB, Franklin DR Jr, et al. HIV-associated neurocognitive disorders persist in the era of potent antiretroviral therapy: CHARTER Study. Neurology. 2010;75:2087-2096.

27. Baldewicz TT, Leserman J, Silva SG, et al. Changes in neuropsychological functioning with progression of HIV-1 infection: results of an 8-year longitudinal investigation. AIDS Behav. 2004;8:345-355.

28. Fazeli PL, Marceaux JC, Vance DE, Slater L, Long CA. Predictors of cognition in adults with HIV: implications for nursing practice and research. J Neurosci Nurs. 2011;43:36-50.

29. Hardy DJ, Vance DE. The neuropsychology of HIV/AIDS in older adults. Neuropsychol Rev. 2009;19:263-272.

30. Wilkie FL, Goodkin K, Khamis I, et al. Cognitive functioning in younger and older HIV-1- infected adults. JAcquir Immune Defic Syndr. 2003;33(Suppl):93-105

31. Vance DE, Struzick TC. Addressing risk factors of cognitive impairment in adults aging with HIV: a social work model. J Gerontol Soc Work. 2007;49:51-77.

32. Shelburne SA III, Hamill RJ. The immune reconstitution inflammatory syndrome. AIDS. 2003;5:67-79.

33. Durvasula RS, Myers HF, Mason K, Hinkin C. Relationship between alcohol use/abuse, HIV infection and neuropsychological performance in African American men. J Clin Exp Neuropsychol. 2006;28:383-404.

34. Basso MR, Bornstein RA. Neurobehavioral consequence of substance abuse and HIV infection. J Psychopharmacol. 2000;14:228-237.

35. Parsons TD, Tucker KA, Hall CD, et al. Neurocognitive functioning and HAART in HIV and hepatitis $\mathrm{C}$ virus co-infection. AIDS 2006;20:1591-1595.

36. Fields RD. The other brain: from dementia to schizophrenia, how new discoveries about the brain are revolutionizing medicine and science. New York: Simon and Schuster; 2009.

37. Vance DE. Cortical and subcortical dynamics of aging with HIV infection. Percept Mot Skills. 2004;98:647-655.

38. Vance DE, Ross JA, Moneyham L, Farr KF, Fordham P. A model of cognitive decline and suicidal ideation in adults aging with HIV. J Neurosci Nurs. 2010;42:150-156.

39. Fuchs E, Czéh B, Kole MH, Michaelis T, Lucassen PJ. Alterations of neuroplasticity in depression: the hippocampus and beyond. Eur Neuropsychopharmacol. 2004;14:S481-S490.

40. Reid IC, Stewart CA. How antidepressants work: new perspectives on the pathophysiology of depressive disorder. Br J Psychiatry. 2001;178:299-303.
41. Young AH, Gallagher P, Watson S, Del-Estal D, Owen BM, Ferrier IN. Improvements in neurocognitive function and mood following adjunctive treatment with mifepristone (RU-486) in bipolar disorder. Neuropsychopharmacol. 2004;29:1538-1545.

42. Loue S, Sajatovic M, Mendez N. Substance use and HIV risk in a sample of severely mentally ill Puerto Rican women. J Immigr Minor Health. 2011. Epub ahead of print.

43. Levounis P, Galanter M, Dermatis H, Hamowy A, De Leon G. Correlates of HIV transmission risk factors and considerations for intervention in homeless, chemically addicted and mentally ill patients. $J$ Addict Dis. 2002;21:61-72.

44. Thompson SC, Checkley GE, Hocking JS, Crofts N, Mijch AM, Judd FK. HIV risk behavior and HIV testing of psychiatric patients in Melbourne. Aust NZ J Psychiatry. 1997;31:566-576.

45. Meade CS, Graff FS, Griffin ML, Weiss RD. HIV risk behavior among patients with co-occurring bipolar and substance use disorders: associations with mania and drug abuse. Drug Alcohol Depend. 2008;92:296-300.

46. Cooperman NA, Simoni JM. Suicidal ideation and attempted suicide among women living with HIV/AIDS. J Behav Med. 2005;28: 149-156.

47. Carrico AW, Johnson MO, Morin SF, et al. Correlates of suicidal ideation among HIV-positive persons. AIDS. 2007;21:1199-1203.

48. Nichols JE, Speer DC, Watson BJ, et al. Aging with HIV: psychological, social, and health issues. San Diego, CA: Academic Press; 2002.

49. Kalichman SC, Heckman T, Kochman A, Sikkema K, Bergholte J. Depression and thoughts of suicide among middle-aged and older persons living with HIV-AIDS. Psychiatr Serv. 2000;51:903-907.

50. Buunk BP, Hoorens V. Social support and stress: the role of social comparison and social exchange processes. Br J Clin Psychol. 1992;31:445-457.

51. Poindexter C, Shippy RA. Networks of older New Yorkers with HIV: fragility, resilience, and transformation. AIDS Patient Care STDs. 2008;22:723-733.

52. Shippy RA, Karpiak SE. The aging HIV/AIDS population: fragile social networks. Aging Ment Health. 2005;9:246-254.

53. Nicholson NR Jr. Social isolation in older adults: an evolutionary concept analysis. J Adv Nurs. 2009;65:1342-1352.

54. Rabkin JG, McElhiney M, Ferrando SJ, Van Gorp W, Lin SH. Predictors of employment of men with HIV/AIDS: a longitudinal study. Psychosom Med. 2004;66:72-78.

55. Scott S, Constantine LM. The Lazarus Syndrome: a second chance for life with HIV infection. J Am Pharm Assoc. 1999;3:462-466.

56. Furunes T, Mykletun RJ. Age discrimination in the workplace: validation of the Nordic Age Discrimination Scale (NADS). Scand J Psychol. 2010;51:23-30.

57. Keogh M. Management and organizational barriers in the acquisition of computer usage skills by mature age workers. Australas J Ageing. 2009;28:122-126.

58. Crystal S, Akincigil A, Sambamoorthi U, et al. The diverse older HIVpositive population: a national profile of economic circumstances, social support, and quality of life. J Acquir Immune Defic Syndr. 2003;33:S76-S83.

59. Zebrack BJ, Zeltzer LK. Living beyond the sword of Damocles: surviving childhood cancer. Expert Rev Anticancer Ther. 2001;1: 163-164.

60. Vance DE, Struzick TC, Masten J. Hardiness, successful aging, and HIV: implications for social work. J Gerontol Soc Work. 2008;51:260-283.

61. Dolbier CL, Cocke RR, Leiferman JA, et al. Differences in functional immune responses of high vs low hardy healthy individuals. J Behav Med. 2001;24:219-229.

62. Lambert CE, Lambert VA. Psychological hardiness: state of the science. Holist Nurs Pract. 1999;13:11-19.

63. Vance DE. Spirituality of living and aging with HIV: a pilot study. $J$ Relig Gerontol. 2006;19:57-74. 
64. Vance DE, Woodley RA. Spiritual expressions of coping in adults with HIV: implications for successful aging. J Relig Disabil Health. 2008;12:37-57.

65. Ettenhofer ML, Hinkin CH, Castellon SA, et al. Aging, neurocognition, and medication adherence in HIV infection. Am J Geriat Psychiatry. 2009; 17:281-290.

66. Vance DE, Fazeli PL, Ross LA, Ackerman ML. The effect of visual speed of processing training on middle-aged and older adults with HIV. Paper presented at the Gerontological Society of America Annual Conference; 2010 Nov 19-23; New Orleans, LA.
67. Waters L, Nelson M. Long-term complications of antiretroviral therapy: lipoatrophy. Int J Clin Pract. 2007;61(6):999-1014.

68. Editorial. Report from Vienna: progress and challenges. Achieve: Quarterly J HIV Prevention, Treatment, Politics. 2010:19.

\section{Publish your work in this journal}

Clinical Interventions in Aging is an international, peer-reviewed journal focusing on evidence-based reports on the value or lack thereof of treatments intended to prevent or delay the onset of maladaptive correlates of aging in human beings. This journal is indexed on PubMed Central, MedLine, the American Chemical Society's 'Chemical Abstracts
Service' (CAS), Scopus and the Elsevier Bibliographic databases. The manuscript management system is completely online and includes a very quick and fair peer-review system, which is all easy to use. Visit http://www.dovepress.com/testimonials.php to read real quotes from published authors.

Submit your manuscript here: http://www.dovepress.com/clinical-interventions-in-aging-journal 